\title{
Auditory brainstem function in microcephaly related to Zika virus infection
}

Dimitri Marques Abramov, MD, PhD, Tania Saad, MD, PhD, Saint-Clair Gomes-Junior, PhD, Daniel de Souza e Silva, MD, MSc, Izabel Araújo, BS, Maria Elizabeth Lopes Moreira, MD, PhD, and Vladimir V. Lazarev, PhD, DSC

Neurology ${ }^{\circledR}$ 2018;90:e1-e9. doi:10.1212/WNL.0000000000004974

\section{Abstract}

\section{Objective}

To study the effect of prenatal Zika virus $(\mathrm{ZV})$ infection on brainstem function reflected in brainstem auditory evoked potentials (BAEPs).

\section{Methods}

In a cross-sectional study in 19 children (12 girls) with microcephaly related to $\mathrm{ZV}$ infection, aged between 12 and 62 weeks, the brainstem function was examined through BAEPs. The latencies of wave peaks I, III, and V of the left and right ears $(n=37)$ were standardized according to normative data, and compared between them by 2 -tailed $t$ test. The confounding variables (cephalic perimeter at the born and chronological age) were correlated with the normalized latencies using Pearson test.

\section{Results}

All patients showed, in general, clear waveforms, with latencies within 3 SDs of the normative values. However, statistically increased latencies of waves I and III (I > III, $p=0.031$ ) were observed, relative to wave $\mathrm{V}(p<0.001)$, the latter being closer to respective normative value. The latency of wave I was observed to increase with age $(r=0.45, p=0.005)$. The waves, in turn, did not depend on cephalic perimeter.

\section{Conclusions}

These results are consistent with the functional normality of the brainstem structure and its lack of correlation with microcephaly, suggesting that the disruption produced by the ZV infection does not act in the cell proliferation phase, but mostly in the processes of neuronal migration and differentiation in the telencephalon. 


\section{Glossary}

ANOVA $=$ analysis of variance; BAEP $=$ brainstem auditory evoked potential; $\mathbf{C M V}=$ cytomegalovirus; TORCH-S = toxoplasmosis, other agents, rubella, cytomegalovirus, herpes simplex; ZV = Zika virus.

The most devastating consequence of vertical infection by Zika virus $(\mathrm{ZV})$ is microcephaly, with cephalic perimeter lower than 3 SDs from the normative mean, ${ }^{1,2}$ resembling other types of microcephaly. ${ }^{2-4}$

Prenatal microcephaly is likely to be caused by primary reduction of neuronal populations ${ }^{5-7}$ or dendritic atrophy, when the brain does not develop in the postnatal period. ${ }^{5}$ Various forms of microcephaly are associated with brainstem hypoplasia. ${ }^{4,8-10}$

Pathophysiology of microcephaly associated with ZV and other related viruses is not yet fully understood. The cytomegalovirus (CMV) may have high tropism for progenitor and radial glia cells, ${ }^{11}$ with inflammation in the inner ear affecting hearing. ${ }^{12}$ Similar to CMV, ZV has shown high tropism for neuronal progenitor cells in vitro ${ }^{13,14}$ and in in vivo, ${ }^{15-17}$ producing changes in the mitotic cycle, cell death, and defects in neuronal migration, probably causing interruption of brain development. ${ }^{18,19}$

In spite of the numerous reports on brainstem hypoplasia in children with ZV-associated ${ }^{2,20-22}$ and other cases of microcephaly, ${ }^{4,8-10}$ information on brainstem neurophysiology is lacking. Short-latency brainstem auditory evoked potentials (BAEPs) allow an assessment of brainstem changes by contiguity, extrapolating to the auditory system. ${ }^{23}$ Brainstem evoked response audiometry has allowed observing alterations compatible with brainstem dysfunction in children with microcephaly. ${ }^{24}$ Another study assessed auditory function in microcephaly with high risk for sensorineural hearing loss. ${ }^{25}$ Data reported in the literature regarding $\mathrm{ZV}$-associated microcephaly in children are restricted to postnatal hearing loss. ${ }^{26}$

The objective of this research was to analyze the BAEPs in children with ZV-associated microcephaly, thus studying the brainstem function and its dependence on chronological age and cephalic perimeter.

\section{Methods}

\section{Study design}

A cross-sectional study from the Vertical Exposure to Zika Virus and Its Consequences for Child Neurodevelopment cohort was performed to evaluate the brainstem function of microcephalic children with gestational $\mathrm{ZV}$ infection through BAEPs.

\section{Standard protocol approvals, registrations, and patient consents}

The study was carried out in the cohort of children followed by the multidisciplinary study of the National Institute of
Women, Children and Adolescents Health Fernandes Figueira, called Vertical Exposure to Zika Virus and Its Consequences for Child Neurodevelopment (NCT 03255369). These children underwent BAEP examination as part of their assessment. The project was duly approved by the research ethics committee of this institution under number CAAE 52675616.0.0000.5269 and the children's guardians gave written informed consent for participation in the study, according to the local and international standards.

\section{Setting}

All participants were recruited from Ambulatory Child Neurology of the National Institute of Women, Children and Adolescents Health Fernandes Figueira from August 2016 to February 2017 among those referred to the Laboratory of Neurobiology and Clinical Neurophysiology of the same institute for examination of auditory function.

\section{Participants}

Twenty-three children with microcephaly related to ZV infection were included in the study. Microcephaly was classified according to cephalic perimeter values as established by the Child Growth Standards. ${ }^{27}$

Children with hydrocephalus or associated hydranencephaly and children with clinical diagnosis for other toxoplasmosis, other agents, rubella, cytomegalovirus, herpes simplex (TORCH-S) infections were excluded from the study. The children's ears that presented signals of conductive deficit or absence of recognizable evoked waves were also excluded from the data analysis.

\section{Variables}

We observed as principal outcome the latencies of the wave peaks I, III, and V, interpeak latency I-V of the ears of the microcephalic children, and their dependence on the confounder variables (chronological age at the examination and cephalic perimeter at birth, obtained from medical records).

\section{Evoked potential examination procedures}

Children were examined during spontaneous sleep or wakefulness, comfortably stabilized in the caregiver's lap and under low light.

A Viking Quest Nicolet and Audiometric Headphones TDH39P 296D000-4 (Telephonics, Farmingdale, NY), with 2 channels for capture, were used. The electrodes were positioned on the right and left mastoid (channels A1 and A2, respectively), the reference electrode at the vertex $(\mathrm{Cz})$, and the circuit was grounded at frontopolar midline position Fpz. The impedance values were below $10.0 \mathrm{k} \Omega$ and the low-pass $(3 \mathrm{kHz})$, high pass $(30 \mathrm{~Hz})$, and notch $(60 \mathrm{~Hz})$ online filters were employed, with a rejection interval of $\pm 10 \mu \mathrm{V}$. 
The brainstem evoked potentials were obtained under click stimuli (nominal square waves with $100 \mu$ s period generating biphasic electromagnetic pulse for headphones membranes) in the rarefaction and condensation polarities, under a stimulation rate of $11.1 \mathrm{~Hz}$ and intensity of $70 \mathrm{~dB} \mathrm{nHL}$, with contralateral mask (at $30 \mathrm{~dB} \mathrm{nHL}$ ), according to the methodology to obtain the normative values adopted in this study for the analysis of latencies. ${ }^{28} \mathrm{Up}$ to 4,000 sweeps were obtained for each polarity according to the cooperation of the patient, wave acquisition signal quality, and amplitude.

\section{Bias control}

Peaks I, III, and V were manually detected by 2 experienced professional examiners independently of each other in order to reduce the bias associated with interpretation subjectivity. When detection was not coincident, we considered the arithmetic average of the 2 estimated latencies. Further, when any of the examiners declared a latency to be undetectable, that found by the other examiner was used (table 1).

\section{Study sample}

The patients included in the study came from the main cohort, which currently has 291 children, of whom 83 were diagnosed with microcephaly (38 with a diagnosis confirmed by PCR and 44 with a clinical diagnostic). Of the 23 patients with microcephaly referred for BAEP examination, 19 were included in the study (see Results).

\section{Data analysis}

The clinical normality assessment for each component and for the latency difference (time interval) between waves I and V was evaluated within the range delimited by the mean (3 SDs) of the normative data obtained by Picton et al. ${ }^{28}$ corresponding to the ages of $6,12,26,52$, and 108 weeks. These normative values, linearly interpolated for 1-week intervals (table e-1, http://links.lww.com/WNL/A149), were used in the normality evaluation as well as in the statistical analysis, resulting in 103 different values for the mean (SD). Table 1 lists the latency and age data for all 19 children, with the altered latencies highlighted according to the adopted evaluation criterion.

Since the sample was heterogeneous with respect to age and, therefore, the mean (SD) normative values varied, the number of SDs relative to the mean (D) exhibited by each individual for each latency value were used. $\mathrm{D}$ was calculated as

Table 1 Descriptive data of patients and latencies of waves I, III, and V, and difference between waves I and V (ms)

\begin{tabular}{|c|c|c|c|c|c|c|c|c|c|c|c|c|c|}
\hline \multirow[b]{2}{*}{ Code } & \multirow{2}{*}{$\begin{array}{l}\text { Age, } \\
\text { wk }\end{array}$} & \multirow[b]{2}{*}{ Sex } & \multirow{2}{*}{$\begin{array}{l}\text { Trimester of } \\
\text { maternal } \\
\text { infection }\end{array}$} & \multirow{2}{*}{$\begin{array}{l}\text { Form of } \\
\text { diagnosis }\end{array}$} & \multirow{2}{*}{$\begin{array}{l}\text { Cephalic } \\
\text { perimeter } \\
\text { at birth, cm }\end{array}$} & \multicolumn{4}{|c|}{ Left ear } & \multicolumn{4}{|c|}{ Right ear } \\
\hline & & & & & & I & III & v & I-V & I & III & v & I-V \\
\hline 1 & 62 & $\mathrm{~F}$ & 1 & Clinical & 26.00 & 2.05 & 4.09 & 5.75 & 3.70 & 2.25 & 4.10 & 5.85 & 3.61 \\
\hline 2 & 13 & M & 1 & PCR & 29.00 & 1.99 & 4.45 & 6.60 & 4.36 & 1.96 & 4.50 & 6.20 & 4.24 \\
\hline 3 & 28 & $\mathrm{~F}$ & 1 & PCR & 25.00 & 1.80 & 4.89 & 6.70 & 4.90 & 1.80 & 4.98 & 7.05 & 5.25 \\
\hline 4 & 18 & M & - & Serology (IgG+) & 29.00 & 1.90 & 4.15 & 6.50 & 4.60 & 1.94 & 4.50 & 6.60 & 4.67 \\
\hline 5 & 19 & $\mathrm{~F}$ & 1 & PCR & 31.50 & 1.95 & 4.50 & 6.10 & 4.15 & 1.80 & 4.40 & 5.90 & 4.10 \\
\hline 6 & 59 & M & 1 & Clinical & 30.00 & 2.01 & 4.30 & 6.05 & 4.04 & 2.00 & 4.20 & 5.80 & 3.80 \\
\hline 7 & 12 & $\mathrm{~F}$ & 1 & Serology (IgG+) & 28.00 & 1.95 & 4.68 & 6.65 & 4.70 & 1.90 & 4.55 & 6.70 & 4.80 \\
\hline 8 & 61 & M & - & PCR & 26.00 & 2.05 & 4.23 & 5.78 & 3.73 & 2.13 & 4.40 & 5.80 & 3.67 \\
\hline 9 & 14 & M & - & Inconclusive & 25.00 & 1.90 & 4.50 & 6.15 & 4.25 & 1.79 & 4.34 & 6.30 & 4.52 \\
\hline 10 & 34 & $\mathrm{~F}$ & 3 & PCR & 27.00 & 1.80 & 4.20 & 5.85 & 4.05 & 1.77 & 4.02 & 5.90 & 4.13 \\
\hline 11 & 27 & $\mathrm{~F}$ & - & Inconclusive & - & 1.74 & 4.77 & 6.83 & 5.13 & 1.80 & 4.50 & 6.20 & 4.40 \\
\hline 12 & 59 & M & 1 & Clinical & 28.00 & 2.25 & 4.30 & 6.25 & 4.00 & 2.22 & 4.30 & 6.42 & 4.20 \\
\hline 13 & 13 & $\mathrm{~F}$ & 1 & PCR & 30.50 & - & - & - & - & 1.85 & 4.44 & 6.23 & 4.38 \\
\hline 14 & 36 & $\mathrm{~F}$ & 1 & Clinical & 30.00 & 2.00 & 4.40 & 6.25 & 4.25 & 1.75 & 4.20 & 5.80 & 4.15 \\
\hline 15 & 24 & M & 1 & Clinical & 27.00 & 1.85 & 4.53 & 6.20 & 4.35 & 1.90 & 4.40 & 6.05 & 4.15 \\
\hline 16 & 16 & $\mathrm{~F}$ & 1 & Clinical & - & 1.95 & 3.84 & 6.00 & 4.20 & 1.95 & 4.20 & 6.30 & 4.35 \\
\hline 17 & 17 & $\mathrm{~F}$ & 2 & Clinical & 27.00 & 2.25 & 4.38 & 6.10 & 3.85 & 2.19 & 4.35 & 6.10 & 3.91 \\
\hline 18 & 17 & $\mathrm{~F}$ & 1 & PCR & - & 2.70 & 5.55 & 7.43 & 4.73 & 1.60 & 4.53 & 6.67 & 5.05 \\
\hline 19 & 33 & $\mathrm{~F}$ & 1 & PCR & 30.00 & 2.30 & 4.14 & 6.30 & 4.01 & 2.00 & 4.10 & 6.30 & 4.30 \\
\hline
\end{tabular}

Abbreviation: IgG = immunoglobulin G. 


$$
\mathrm{D}_{\mathrm{i}}=\left(\mathrm{L}_{\mathrm{i}}-\mathrm{x}_{\mathrm{i}}\right) / \mathrm{s}_{\mathrm{i}},
$$

where $L$ is the latency of a given peak or time interval between peaks of patient $i$, and $x$ and $s$ are the normative mean and SD, respectively, for the age of individual $i$ in weeks.

\section{Statistical methods}

We performed preliminary analysis with the nonparametric Mann-Whitney $U$ test (due to small sample size of 19 , and the presence of missing values) to infer on a possible significant binaural difference. In case a statistically significant difference between ears was not observed (see Results), these could be analyzed together by comparing the individual deviations, D, of waves I, III, and V, through parametric analysis of variance (ANOVA) tests, for repeated measurements with post hoc analysis with the 2 -tailed $t$ test, provided homogeneity of the variances was not rejected (Levene test) and assuming the normality of the distributions (36 ears). In this case, we performed the Pearson correlation of the wave latencies of ears with age at the time of examination. It is noted that in the case of nonhomogeneous variances or rejection of normality, nonparametric tests (Friedman, Wilcoxon for repeated measurements, and Spearman test) would have to be used.

\section{Results}

\section{Descriptive data}

Of the 23 patients recruited, 19 were included in the study and 4 were excluded according to the exclusion criteria (2 presented hydranencephaly and 2 evidenced TORCH-S syndrome). In 2 children, the diagnosis of $\mathrm{ZV}$ infection was not conclusive, but they were included in the sample, since any other cause of microcephaly was excluded (TORCH-S inclusive).

There were 7 boys and 12 girls, aged 29.57 (17.84) weeks (mean [SD], between 12 and 62 weeks), $28.06(2.02) \mathrm{cm}$ cephalic perimeter at birth (3 missing values). With regard to gestational period at infection, 13 children were infected in the first trimester, 1 in the second trimester, 1 in the third trimester, and 4 mothers were unaware of the probable date of infection, as they were asymptomatic. Among the children included in this study, the PCR results of 11 were positive, the serology (immunoglobulin $\mathrm{G}+$ ) results of 2 were positive, and the clinical status of 5 were compatible with Zika syndrome during gestation, according to $\mathrm{PAHO} / \mathrm{WHO}$ guidelines. ${ }^{29}$ All children were from the metropolitan region of Rio de Janeiro, of different socioeconomic status.

The waves in the BAEPs exhibited clear definition and amplitude, from a qualitative perspective (figure 1, examples of waves obtained). In general, only 1 girl (patient 13 , examined at age 13 weeks) among the patients in the group showed substantial abnormality in the left ear, with isoelectric tracings up to the intensity of $90 \mathrm{~dB} \mathrm{nHL}$ stimulation, consistent with complete deafness (figure 1 and table 1). Measurements of this ear were excluded from the analysis. Patient 18 (a girl, examined at 17 weeks of age, table 1) showed conductive alteration in the left ear (increase of the latency of peak I relative to the normalized data, followed by increase of latencies of peaks III and V without change of the time interval between peaks I and V, which matched that of the contralateral ear, whose measurements were within the normative standards). Measurements of this ear were also excluded from the analysis.

\section{Main results}

Based on the criterion of the 3 SDs of the normative values, ${ }^{28}$ the only observed abnormality was that between peaks I and $\mathrm{V}$ of the right ear of patient 1 (girl, examined at age 62 weeks) at the expense of peak I and V latencies being higher and lower, respectively, than the corresponding normative values, although both within the range of 3 SDs.

Comparison of the latencies of the right and left ears of the sample showed no significant differences $(p \geq 0.21$ for all comparisons between right and left ears). Therefore, measurements of the remaining ears were taken together in the analysis (figure 2).

Results showed that almost all latencies were higher than the normative value for wave I, in both ears (1.27 [0.84] of the normative data), and nearly all latencies for wave III followed the behavior of wave I (0.80 [0.79]). Latencies of wave V, in turn, were around the normative value $(0.09[1.00])$. Thus, nearly all latencies between peaks I and $\mathrm{V}$ were lower than the normative value $(-1.05[1.30])$. The values of $\mathrm{D}$ (in latency SDs) were statistically different (ANOVA-R F value $=18.90, p$ $>0.0001$ ); namely, all waves I and III, I and V, and III and V were significantly different (respectively, $p=0.031, p<0.001$, and $p<0.001,2$-tailed $t$ test).

The correlation analysis between the deviations of waves I, III, and $\mathrm{V}$ showed that the latencies of wave I do not correlate with latencies III and V $(r=-0.18, p=0.289$, and $r=-0.09$, $p=0.595$, respectively). However, latencies of waves III and V exhibited a significant correlation $(r=0.64, p<0.0001)$. The greater distance between peaks I and $\mathrm{V}$ was accompanied by the greater absolute latencies of wave III and especially wave V ( $r=0.53, p=0.001$, and $r=0.82, p<0.0001$, respectively) and smaller wave I $(r=-0.59, p>0.001)$.

In contrast to the other absolute latencies and distances between peaks I and V, the latencies of wave peak I increased with age at the time of examination $(r=0.45, p=0.005$, figure 3).

The latencies did not depend on cephalic perimeter $(n=32$ ears, due to 3 missing measures).

\section{Discussion}

In this research, the neurophysiologic study of the brainstem in children with microcephaly, through BAEPs, showed 
A. Patient 4

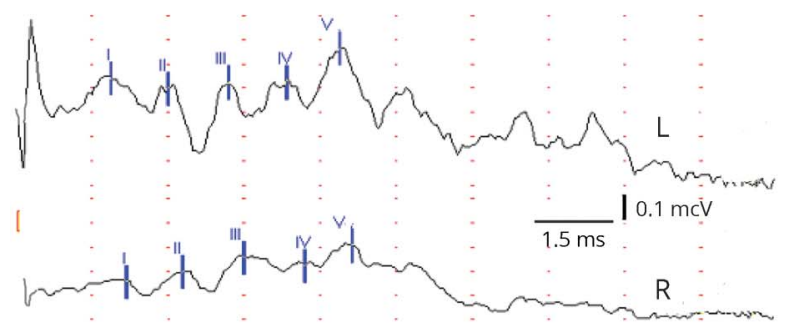

B. Patient 6

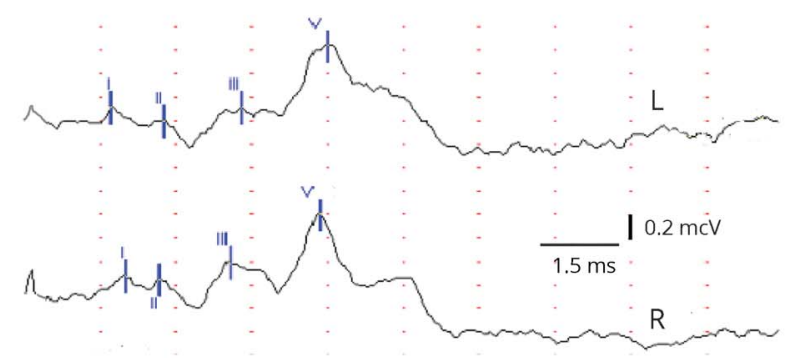

D. Patient 16

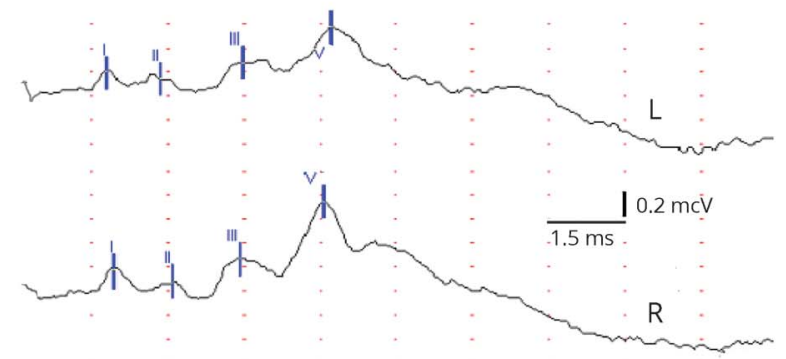

(A) Patient 4: male, 18 weeks, at left 1,326 epochs (rarefaction [Rf]), at right 7,798 epochs (Rf, condensation [Cn]); (B) patient 6: male, 59 weeks, at left 2,215 epochs (Rf, Cn), at right 2,114 epochs (Rf, Cn); (C) patient 13: female, 13 weeks, at left 5,042 epochs (Rf, Cn), at right 4,618 epochs (Rf, Cn); (D) patient 16: male, 24 weeks, at left 2,128 epochs (Rf, Cn); at right 2,067 epochs (Rf, Cn). I-V = wave numbers; L = left auricular channel; R = right auricular channel.

evidence of normality, with no dependence between microcephaly and brainstem function related to the auditory system, reinforced by the lack of significance in the correlation coefficients between cephalic perimeter and the latency of the waves.

A limitation of this study was the unviability of the amplitude analysis, both absolute and relative. Large amplitude variability was observed, even when the latencies were stable. Opposite to latencies, various authors have argued that absolute amplitudes have an interindividual variation too large to be clinically useful. ${ }^{23,30}$ Nevertheless, the ratio of amplitudes is commonly used, although large interindividual variability is still present. ${ }^{30}$ Furthermore, the amplitudes' ratio is sensitive to the electrodes' position. ${ }^{31}$ The overall structure of the brain and the morphology of the head in these children are profoundly altered in a heterogeneous way between patients, which can easily distort the wave amplitudes in unpredictable ways, through both source displacement and reference electrode. Thus, in light of the aforementioned observations, we chose to focus exclusively on the latencies, which are insensitive to changes in the vector axis of the recording derivations.

The sample size was considered another restriction of the study. However, the study was conducted in a reference center for children born with microcephaly related to $\mathrm{ZV}$. Thus, as the sample size continues to increase, it allows for the continuity of the study and the comparison with the results already obtained. Many recruited children showed comorbidities that could interfere with the outcome of the study, compatible with other infections of the TORCH-S group ( 1 case of congenital toxoplasmosis and 2 cases of congenital syphilis were excluded), while others showed an inconclusive clinical or laboratory diagnosis for ZV infection, preventing their inclusion. Four children whose mothers were not aware of any infection were included in the sample, as the laboratory and clinical evaluation was conclusive in establishing a relationship with ZV. Nevertheless, significant information was already obtained through this sample, especially regarding the increase of the latency of wave I with age, which deserves further investigation.

Our results about brainstem functional normality are challenging, considering the substantial disruption of brain development as well as evidence suggesting the action of $\mathrm{ZV}$ on progenitor cells, from the cell proliferation phase. ${ }^{13-19} \mathrm{Al}-$ though the brainstem develops in parallel with the telencephalon in the early stages of embryogenesis, the development of the brainstem does not exhibit the same neuronal migration processes observed in the telencephalon, suggesting that the ZV primarily acts on specific mechanisms 

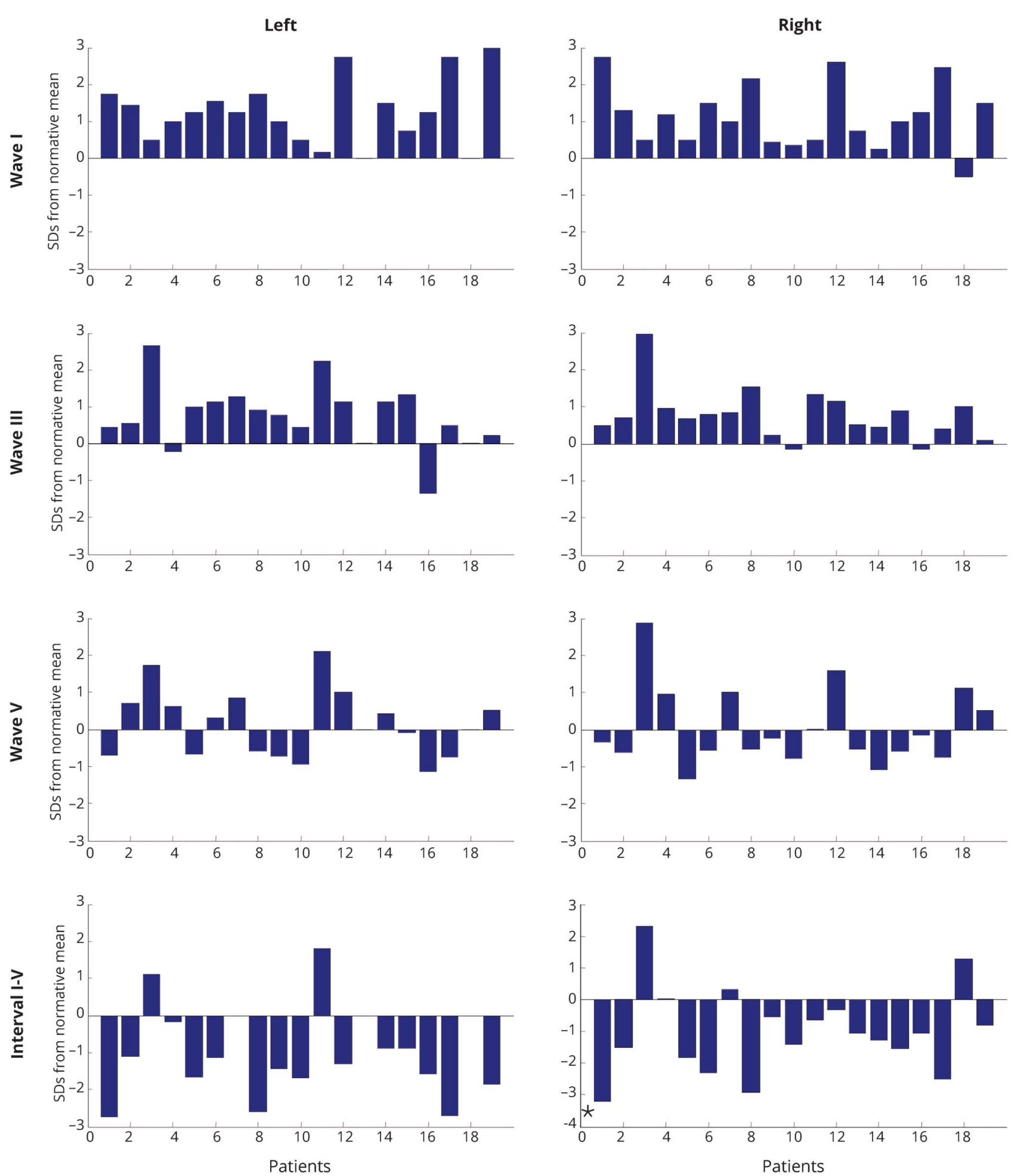

Asterisk points to the only abnormal latency exceeding normative criterion of 3 SDs. Interval I-V = latency difference between waves I and V.

of cerebral cortex formation extending from the first to the third trimester. ${ }^{32,33}$

The development of the neural centers of the sensory systems (including the auditory system), from the brainstem to the neocortex, depends on the stimulation of the afferents, triggering complex biomolecular plasticity processes. ${ }^{33-35}$ The functional organization of the brainstem, as observed in this study, indicates an adequate centripetal development process in children with microcephaly, with a neuronal and synaptic 
Figure 3 Scatterplots and linear regression models for correlation between age and latencies of waves I, III, and V
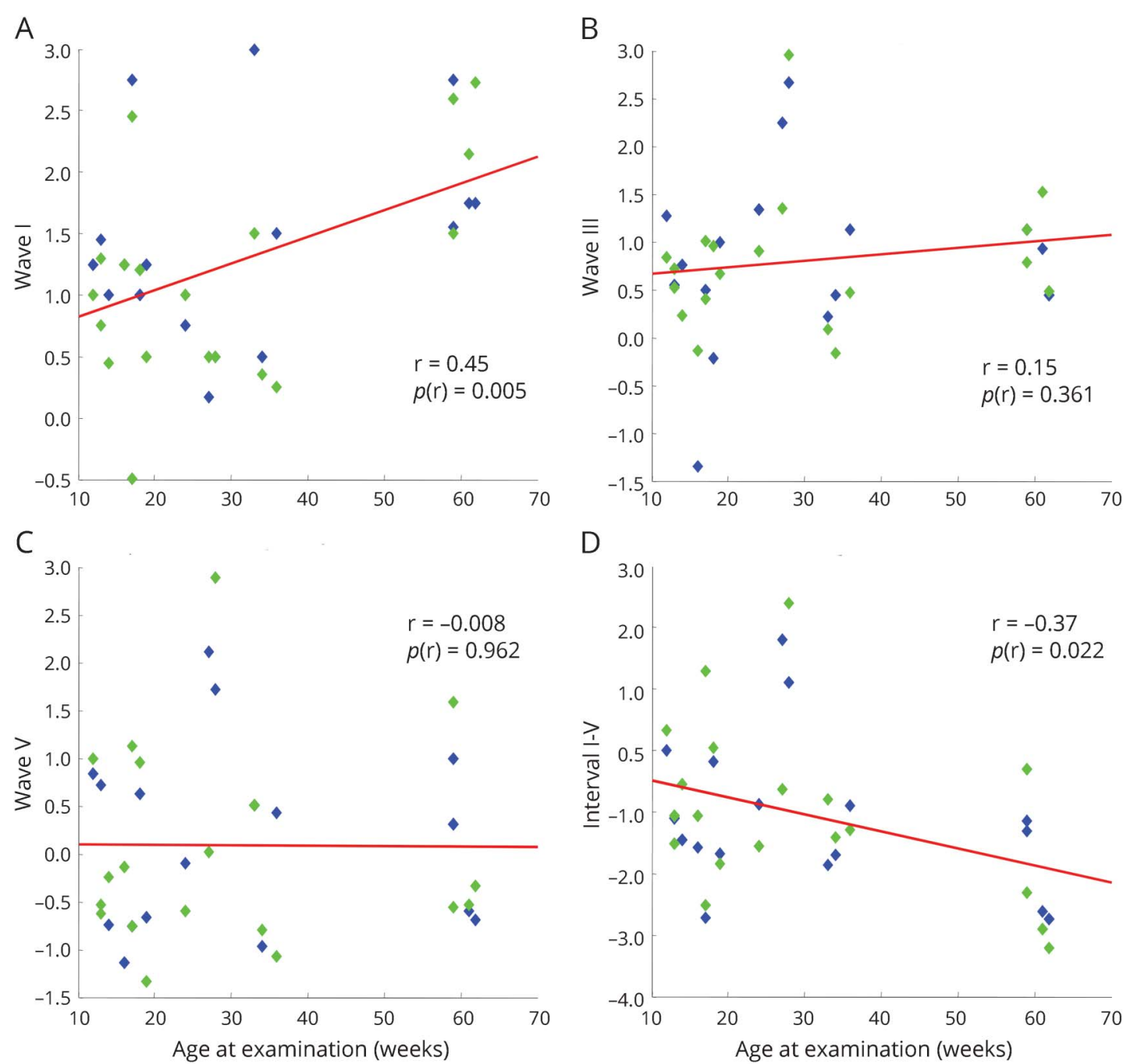

Waves I (A), III (B), and V (C). Blue rhombs represent left ears and green rhombs represent right ears. Interval I-V (D) = latency difference between waves I and V; $p(r)=$ respective $p$ value; $r=$ Pearson correlation coefficient

organization comparable to typical development, restricting the disorder produced by the ZV to more specific processes of CNS development, probably limited to the telencephalon. Perhaps more subtle changes in subcortical auditory pathway development may be assessed using specific frequency stimuli that could detect likely disorders in the formation of the tonotopic maps in the brainstem. ${ }^{36}$

The brainstem function evidenced by the BAEPs in this study can be explained by the normality in the neuronal populations of the pons and midbrain. Thus, the brainstem hypoplasia reported in the literature on microcephaly $y^{4,8-10}$ should be associated with the reduction of fibers in the corticospinal tracts. ${ }^{37}$

The abnormality found in the left ear of patient 13 exhibited a pattern suggestive of peripheral alteration, since wave I was absent and in the contralateral side, any brainstem response was normal, which is an unusual picture for encephalic pathologies. ${ }^{23,31,38}$ Similarly, the change observed in the left ear of patient 18 showed a pattern of conductive alteration. $^{23}$

The magnitude of the latency variations of waves I, III, and $\mathrm{V}$ were dissimilar, suggesting the existence of a functional variation in the auditory circuit of these children, relative to the normative values. The systematic increase of the latency of wave I, coupled with the dissociation of its behavior with the latencies of waves III and V, which showed a direct correlation with each other, support the idea of a peripheral subnormality. This increase of latency seems to be compensated by the neural nuclei of the brainstem, which produce wave III (although latencies are also increased) and wave V. The increase of the latency of wave I, 
without major repercussions in the latency of wave $\mathrm{V}$, suggests sensorineural peripheral alteration, ${ }^{30}$ which manifests in other syndromes acquired through prenatal infections. $^{39,40}$

The increase of the deviation of the normality of latencies of wave I with the age at the time of examination suggests that the $\mathrm{ZV}$ infection leads to a progressive process in peripheral auditory nerve or sensorineural structures. However, this hypothesis could not be confirmed in this study. Larger samples, and the inclusion of children without microcephaly, are currently being investigated to improve the evaluation of this preliminary observation and to confirm the possible subnormality of the latency of wave I.

Thus, this study showed evidence that brainstem physiology is not affected by this congenital infection, even when occurring in the first trimester of pregnancy. This information may contribute to a better understanding of the pathophysiologic mechanism of neuropathies related to ZV.

\section{Author contributions}

Dimitri Abramov: study concept and design, acquisition of data, analysis and interpretation of data, manuscript preparation. Tania Saad: acquisition of data, revision of manuscript for intellectual content. Saint-Clair Gomes-Junior: analysis of data, revision of manuscript for intellectual content. Daniel Souza e Silva: analysis and interpretation of data, revision of manuscript for intellectual content. Izabel Araújo: acquisition of data, revision of manuscript for intellectual content. Maria Elizabeth Lopes Moreira: study concept and design, revision of manuscript for intellectual content. Vladimir V. Lazarev: interpretation of data, revision of manuscript for intellectual content, study supervision.

\section{Acknowledgment}

The authors thank Aldenys Peres Rodrigues and Maria do Socorro Santana for technical support and the personnel of Ambulatory Child Neurology of the National Institute Fernandes Figueira.

\section{Study funding}

Study funded by the National Council for Scientific and Technological Development (Conselho Nacional de Desenvolvimento Científico e Tecnológico).

\section{Disclosure}

The authors report no disclosures relevant to the manuscript. Go to Neurology.org/N for full disclosures.

Received July 23, 2017. Accepted in final form November 6, 2017.

\section{References}

1. da Cunha AJLA, de Magalhães-Barbosa MC, Setta FL, de Andrade Medronho R, Prata-Barbosa A. Microcephaly case fatality rate associated with Zika virus infection in Brazil. Pediatr Infect Dis J 2016;36:1.

2. Zare Mehrjardi M, Keshavarz E, Poretti A, Hazin AN. Neuroimaging findings of Zika virus infection: a review article. Jpn J Radiol 2016;34:765-770.
3. Guha R, Miley L, Aspiri M, Dhamija R. Congenital toxoplasmosis. Pediatr Neurol 2017;70:81-82

4. Basel-Vanagaite L, Dobyns WB. Clinical and brain imaging heterogeneity of severe microcephaly. Pediatr Neurol 2010;43:7-16.

5. Abuelo D. Microcephaly syndromes. Semin Pediatr Neurol 2007;14:118-127.

6. Woods CG. Human microcephaly. Curr Opin Neurobiol 2004;14:112-117.

7. Passemard S, Kaindl AM, Verloes A. Microcephaly. Handb Clin Neurol 2013;111: 129-141.

8. Najm J, Horn D, Wimplinger I, et al. Mutations of CASK cause an X-linked brain malformation phenotype with microcephaly and hypoplasia of the brainstem and cerebellum. Nat Genet 2008;40:1065-1067.

9. Nakamura K, Kato M, Sasaki A, Kanai M, Hayasaka K. Congenital dysplastic microcephaly and hypoplasia of the brainstem and cerebellum with diffuse intracranial calcification. J Child Neurol 2012;27:218-221.

10. Rajab A, Manzini MC, Mochida GH, Walsh CA, Ross ME. A novel form of lethal microcephaly with simplified gyral pattern and brain stem hypoplasia. Am J Med Genet A 2007;143A:2761-2767.

11. Teissier N, Fallet-Bianco C, Delezoide AL, et al. Cytomegalovirus-induced brain malformations in fetuses. J Neuropathol Exp Neurol 2014;73:143-158.

12. Cohen BE, Durstenfeld A, Roehm PC. Viral causes of hearing loss: a review for hearing health professionals. Trends Hear 2014;18

13. Souza BSF, Sampaio GLA, Pereira CS, et al. Zika virus infection induces mitosis abnormalities and apoptotic cell death of human neural progenitor cells. Sci Rep 2016; 6:39775.

14. Garcez PP, Loiola EC, Madeiro da Costa R, et al. Zika virus impairs growth in human neurospheres and brain organoids. Science 2016;352:816-818.

15. Brault JB, Khou C, Basset J, et al. Comparative analysis between flaviviruses reveals specific neural stem cell tropism for Zika virus in the mouse developing neocortex. EBioMedicine 2016;10:71-76.

16. $\mathrm{Li} \mathrm{C}, \mathrm{Xu} \mathrm{D}, \mathrm{Ye} \mathrm{Q}$, et al. Zika virus disrupts neural progenitor development and leads to microcephaly in mice. Cell Stem Cell 2016;19:120-126.

17. Goodfellow FT, Tesla B, Simchick G, et al. Zika virus induced mortality and microcephaly in chicken embryos. Stem Cells Dev 2016;25:1691-1697.

18. Li H, Saucedo-Cuevas L, Shresta S, Gleeson JG. The neurobiology of Zika virus. Neuron 2016;92:949-958.

19. Tang H, Hammack C, Ogden SC, et al. Zika virus infects human cortical neural progenitors and attenuates their growth. Cell Stem Cell 2016;18:587-590.

20. de Fatima Vasco Aragao M, van der Linden V, Brainer-Lima AM, et al. Clinica features and neuroimaging (CT and MRI) findings in presumed Zika virus related congenital infection and microcephaly: retrospective case series study. BMJ 2016;353: i1901.

21. Ramalho Rocha YR, Cavalcanti Costa JR, Almeida Costa P, et al. Radiological characterization of cerebral phenotype in newborn microcephaly cases from 2015 outbreak in Brazil. PLOS Curr Outbreaks 2016 Jun 8.

22. Guillemette-Artur P, Besnard M, Eyrolle-Guignot D, Jouannic JM, Garel C. Prenatal brain MRI of fetuses with Zika virus infection. Pediatr Radiol 2016;46:1032-1039.

23. Chiappa KH, Hill RA. Brain stem auditory evoked potentials: interpretation. In Chiappa KH, editor. Evoked Potentials in Clinical Medicine, 3rd ed. Philadelphia: Lippicott-Raven; 1997:199-268.

24. Das P, Bandyopadhyay M, Ghugare BW, Ghate J, Singh R. Auditory evaluation of the children with microcephaly with brain stem evoked response audiometry (BERA). Indian J Physiol Pharmacol 2010;54:376-380.

25. Olusanya B. Risk of sensorineural hearing loss in infants with abnormal head size. Ann Afr Med 2013;12:98.

26. Leal MC, Muniz LF, Ferreira TSA, et al. Hearing loss in infants with microcephaly and evidence of congenital Zika virus infection-Brazil, November 2015-May 2016. MMWR Morb Mortal Wkly Rep 2016;65:917-919.

27. WHO Multicentre Growth Reference Study Group. WHO Child Growth Standards: Head Circumference-for-Age, Arm Circumference-for-Age, Triceps Skinfold-for-Age and Subscapular Skinfold-for-Age: Methods and Development. Geneva: World Health Organization; 2007.

28. Levy SR. Brainstem auditory evoked potentials in pediatrics. In: Chiappa KH, editor. Evoked Potentials in Clinical Medicine, 3rd ed. Philadelphia: Lippicott-Raven; 1997 271.

29. Pan American Health Organization. Guidelines for Surveillance of Zika Virus Disease and its Complications. Washington, DC: PAHO; 2016.

30. International Federation of Clinical Neurophysiology, Eisen A, Deuschl G. Recommendations for the practice of clinical neurophysiology: guidelines of the In ternational Federation of Clinical Neurophysiology. Electroencephalogr Clin Neurophysiol Suppl 1999;52:1-304.

31. Legatt A. Brainstem auditory evoked potentials: methodology, interpretation and clinical application. In: Aminoff MJ, editor. Aminoff's Electrodiagnosis in Clinica Neurology, 6th ed. Philadelphia: Saunders-Elsevier; 2012:519-552.

32. Stiles J, Jernigan TL. The basics of brain development. Neuropsychol Rev 2010;20: 327-348.

33. Tau GZ, Peterson BS. Normal development of brain circuits. Neuropsychopharmacology 2010;35:147-168.

34. Marrs GS, Spirou GA. Embryonic assembly of auditory circuits: spiral ganglion and brainstem. J Physiol 2012;590:2391-2408.

35. Penn AA, Shatz CJ. Brain waves and brain wiring: the role of endogenous and sensorydriven neural activity in development. Pediatr Res 1999;45:447-458.

36. Saenz M, Langers DRM. Tonotopic mapping of human auditory cortex. Hear Re 2014;307:42-52. 
37. Štrafela P, Vizjak A, Mraz J, et al. Zika virus-associated micrencephaly: a thorough description of neuropathologic findings in the fetal central nervous system. Arch Pathol Lab Med 2017;141:73-81.

38. Celesia GG. Brainstem auditory evoked potentials (BAEPs) and other auditory evoked potentials. In: Schomer DL, da Silva FHL, editors. Niedermeyer's Electroencephalography: Basic Principles, Clinical Applications, and
Related Fields, 6th ed. Philadelphia: Lippincott Williams \& Wilkins; 2011 : 976-1002.

39. Kenna MA. Acquired hearing loss in children. Otolaryngol Clin North Am 2015;48: 933-953.

40. Morzaria S, Westerberg BD, Kozak FK. Systematic review of the etiology of bilateral sensorineural hearing loss in children. Int J Pediatr Otorhinolaryngol 2004;68:1193-1198. 